\title{
Folliculotropic mycosis fungoides treated with topical corticosteroids: A case report and a review of its trichoscopic features
}

\section{Linda Manaa1, Yosra Soua1, Ines Lahouel', Marwa Thabouti', Laila Njim², Monia Youssef', Hichem Belahdjali', Jameleddine Zili' ${ }^{1}$}

${ }^{1}$ Dermatology Department, Fattouma Bourguiba Hospital, University of Medicine, Monastir, Tunisia, ${ }^{2}$ Anatomopathology Department, Fattouma Bourguiba Hospital, University of Medicine, Monastir, Tunisia

Corresponding author: Linda Manaa, MD, E-mail: Lindamanaa6@gmail.com

Sir,

Folliculotropic mycosis fungoides (FMF) represents $5 \%$ of cutaneous lymphomas. It is a rare variant of mycosis fungoides that differs not only by its clinical and histological presentation but also by its prognosis.

It is characterized by an infiltrate of atypical lymphocytes in the perifollicular dermis and hair follicles, with or without mucinosis, while epidermotropism may be completely absent.
Dermoscopic and trichoscopic features in FMF are variable and not well defined.

Herein, we present a unique case of FMF in a female patient with scalp alopecia, which evolved well under topical treatment. We review its trichoscopic findings.

A 64-year-old female presented to our dermatology department with a seven-month history of an alopecic plaque on the scalp. No complaints of itching or
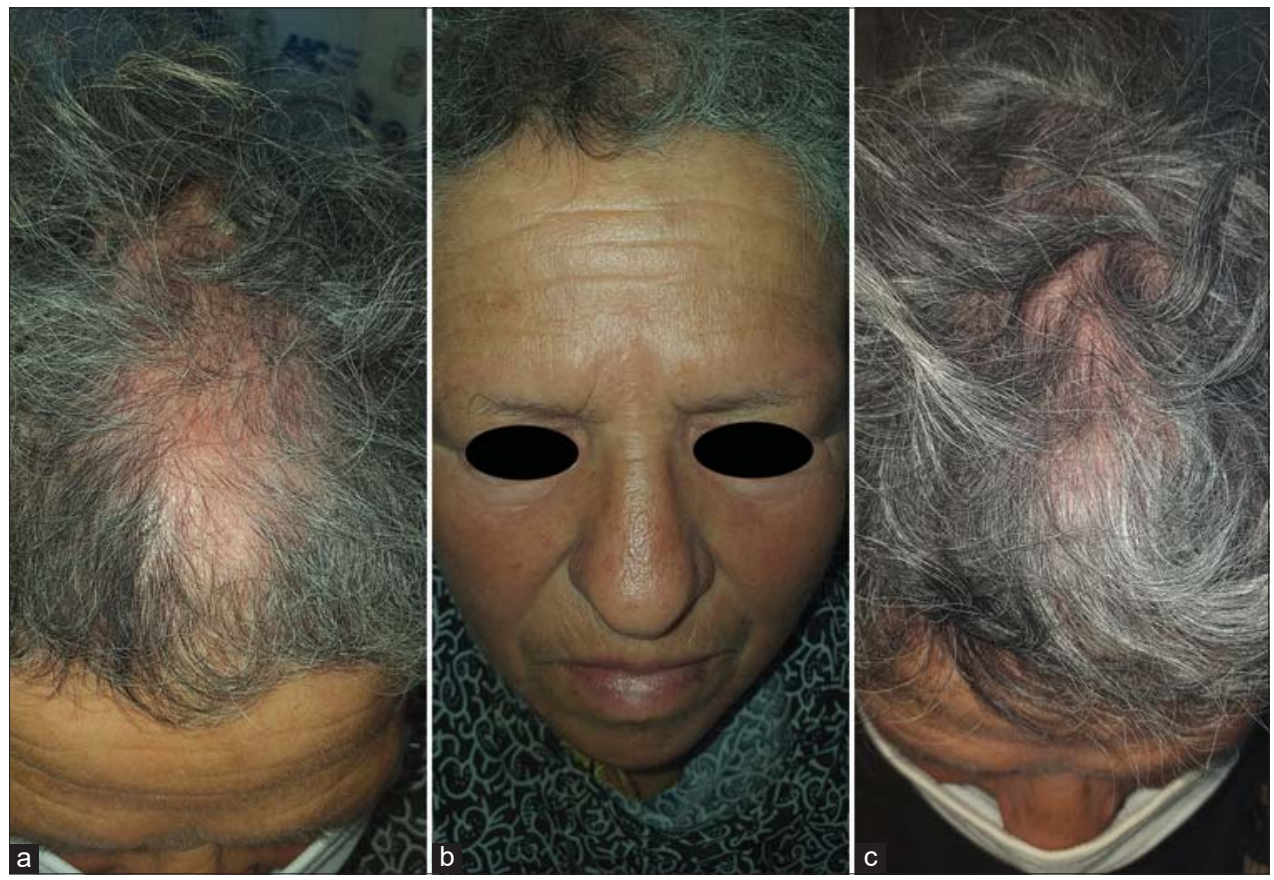

Figure 1: (a) Erythematous, circumscribed alopecia on the scalp; (b) alopecia of the eyebrows; (c) clinical improvement after two months.

\footnotetext{
How to cite this article: Manaa L, Soua Y, Lahouel I, Thabouti M, Njim L, Youssef M, Belahdjali H, Zili J. Folliculotropic mycosis fungoides treated with topical corticosteroids: A case report and review of its trichoscopic features. Our Dermatol Online. 2022;13(1):111-113.

Submission: 08.06.2021; Acceptance: 14.10.2021

DOI: $10.7241 /$ ourd.20221.31
} 
burning were made. There was a history of arterial hypertension and dyslipidemia, which has been treated by oral medication. A physical examination revealed an erythematous, non-infiltrated, circumscribed alopecia in the frontal region of the scalp $8 \mathrm{~cm}$ in size associated with alopecia of the eyebrows (Fig. la and lb).

Trichoscopy showed a decreased number of pilosebaceous units, white scales, an erythematous background, and linear fine vessels (Fig. 2a and 2b).

No other cutaneous lesions were evident. There were no other alopecic or infiltrated plaques, no hyperkeratosis or follicular papules, no acneiform lesions. A histopathological examination of a biopsy specimen revealed an epidermis covered with focally parakeratotic hyperkeratosis. The dermis contained a lymphocytic infiltrate in the follicles and the perifollicular areas. The hair follicles were dissociated by Alcian blue-positive edema. Folliculotropic infiltrate showed positive staining for CD3 and CD4. Some lymphocytes were CD20 ${ }^{+}$(Fig. $\left.3 a-3 c\right)$. The clinical, histological, and immunohistochemical appearance was consistent with the diagnosis of folliculotropic MF. Further examination showed no extracutaneous involvement. A full blood count and liver and kidney parameters were found to be in the normal range. A thoraco-abdomino-pelvic CT scan was without abnormality. Referring to the WHO/

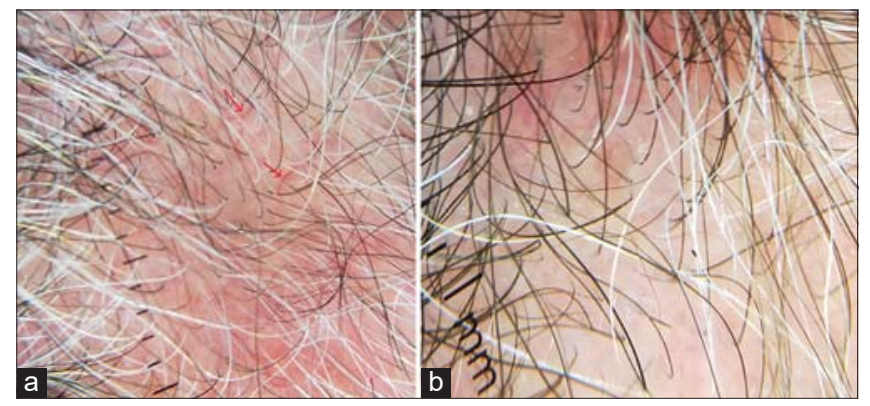

Figure 2: (a) Fine linear vessels and an erythematous background; (b) white scales and a decreased number of follicles.
EORTC classification, the patient's disease was stage IA. We initiated treatment with a high-potency topical corticosteroid with close monitoring. After two months of treatment, improvement was observed (Fig. lc).

FMF presents a wide clinical spectrum. Alopecia is a typical manifestation of FMF occurring in up to $81 \%$ of patients [1]. The involvement of the scalp is not uncommon and may manifest itself by infiltrated inflammatory areas with hair loss, plaques mimicking alopecia areata, less frequently non-inflammatory scarring alopecia with comedo-like lesions [2,3].

Alopecic involvement of the eyebrows, as in our case, is highly characteristic in FMF and may present an early sign of the disease [1].

Several small studies have described dermoscopic patterns of MF and its variants. Dermoscopic features in FMF are heterogeneous, which goes together with the wide clinical spectrum of the disease. Numerous aspects have been described in the literature (Table 1).

Additional observations are needed to identify the trichoscopic spectrum of FMF allowing the differentiation with other diseases causing alopecia.

Recent studies have distinguished indolent (earlystage FMF) and more aggressive (advanced-stage FMF) subgroups $[1,4]$. This classification enabled the adaptation of treatment to each group and the use of less aggressive therapies in the first one.

According to this classification, our patient belonged to the first group, which shows a better response to less aggressive treatment regimens.

The management of FMF is not well defined and depends on its stage. Referring to the literature, local treatments rarely lead to complete remission. This may be attributed to the depth and location of the infiltrate.

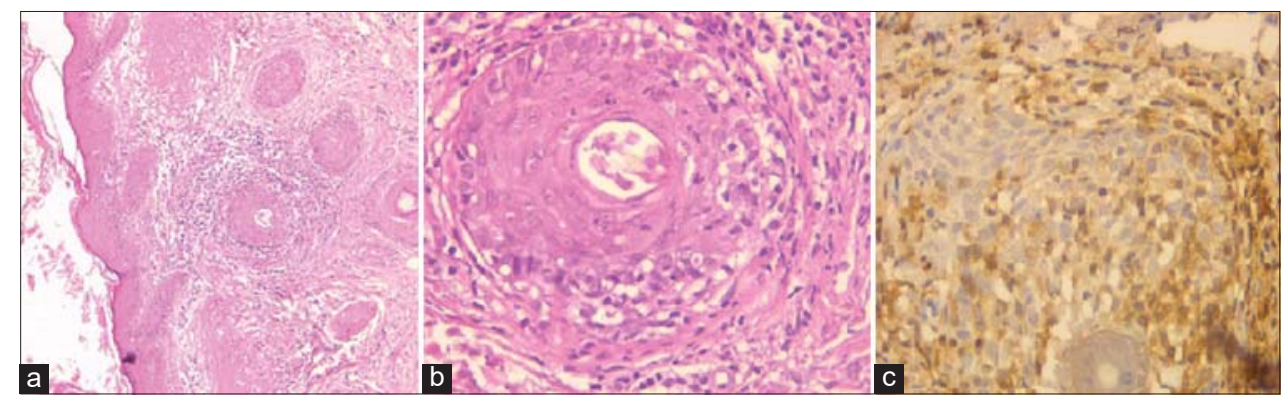

Figure 3: Lymphocytic infiltrate into the follicles and the perifollicular areas (a: H\&E, 100x; b: H\&E, 400x); (c) lymphocytes showing positive staining for CD4 (H\&E, 400x). 
Table 1: Literature review of the dermoscopic features of FMF.

\begin{tabular}{|c|c|c|}
\hline $\begin{array}{l}\text { Author (Year of } \\
\text { publication) }\end{array}$ & Clinical Presentation & Dermoscopic Findings \\
\hline Ghahramani et al. (2018) [5] & $\begin{array}{l}5 \text { patients with FMF. } \\
\text { Lesions on multiple sites (trunk, extremities, buttocks). }\end{array}$ & $\begin{array}{l}\text { - Perifollicular accentuation (100\%) } \\
\text { - Comedo-like openings }(60 \%) \\
\text { - White structureless areas }(60 \%) \\
\text { - Fine short linear vessels }(40 \%) \\
\text { - Dotted vessels }(40 \%) \\
\text { - White scale }(80 \%)\end{array}$ \\
\hline Toncic et al. (2018) [6] & Erythematous patch on the right side of a forehead. & - Perifollicular accentuation seen as a white halo around the follicles \\
\hline Slawinska et al. (2018) [2] & $\begin{array}{l}\text { Extensive patchy alopecia of the scalp (erythematous areas } \\
\text { of hair loss with scaling). }\end{array}$ & $\begin{array}{l}\text { - A decreased number of pilosebaceous units mostly single hair } \\
\text { - Milky-white globules } \\
\text { - Yellow dots with or without centrally located black dots/broken hairs } \\
\text { - White dots and lines } \\
\text { - White and yellow scale } \\
\text { - Short hair with split-ends } \\
\text { - Short hair with triangular ends } \\
\text { - Short, broken hair } \\
\text { - Pigtail-appearance hair } \\
\text { - Short hairs broken at the same or different level. }\end{array}$ \\
\hline Caccavale et al. (2019) [4] & $\begin{array}{l}\text { Comedo-like lesions, follicular papules, pustules located on } \\
\text { the trunk, and an alopecic patch on the left forearm. }\end{array}$ & $\begin{array}{l}\text { - Comedo-like lesions surrounded by perifollicular erythema } \\
\text { - White or pinkish structureless areas replacing lost hair follicles } \\
\text { - Fine short linear, glomerular and dotted vessels }\end{array}$ \\
\hline Geller et al. (2019) [3] & $\begin{array}{l}\text { Patient 1: follicular papules with alopecia on the thigh } \\
\text { Patient 2: erythematous plaque with alopecia on the scalp } \\
\text { Patient 3: erythematous follicular papules with a central } \\
\text { scale (keratosis pilaris-like) on the buttocks. } \\
\text { Patient 4: facial erythematous follicular papules }\end{array}$ & $\begin{array}{l}\text { - Patient 1: orange-pink perifollicular clods with peripheral scale and } \\
\text { central broken hairs } \\
\text { - Patient 2: perifollicular halos and broken hairs } \\
\text { - Patient 3: short fine vessels and perifollicular scale overlying a } \\
\text { yellowish background, surrounding central keratotic plugs } \\
\text { - Patient 4: a white and hyperpigmented halo around the follicles } \\
\text { and perifollicular scale and white clods }\end{array}$ \\
\hline Toncic et al. (2020) [7] & $\begin{array}{l}\text { Patient 1: erythematous patches and plaques on the neck, } \\
\text { face, arms, and back. } \\
\text { Patient 2: erythematous papules, plaques, comedones, and } \\
\text { milia localized on the neck and chest. }\end{array}$ & $\begin{array}{l}\text { - Obliteration of the follicles, follicular accentuation, and follicular } \\
\text { plugging } \\
\text { - Loss of terminal follicles } \\
\text { - Comedo-like openings } \\
\text { - Interconnected regular-appearing structureless patches } \\
\text { - Bluish structures (when eccrine glands are affected) }\end{array}$ \\
\hline Our case & Inflammatory alopecic plaque on the scalp. & $\begin{array}{l}\text { - A decreased number of pilosebaceous units, white scales, an } \\
\text { erythematous background, and linear fine vessels }\end{array}$ \\
\hline
\end{tabular}

In our patient, given the early stage of the disease, treatment with topical corticosteroids was sufficient to control the lesions.

\section{Consent}

The examination of the patient was conducted according to the principles of the Declaration of Helsinki.

The authors certify that they have obtained all appropriate patient consent forms, in which the patients gave their consent for images and other clinical information to be included in the journal. The patients understand that their names and initials will not be published and due effort will be made to conceal their identity, but that anonymity cannot be guaranteed.

\section{REFERENCES}

1. Van Santen S, Roach REJ, van Doorn R, Horváth B, Bruijn MS, Sanders CJG, et al. Clinical Staging and Prognostic Factors in Folliculotropic Mycosis Fungoides. JAMA Dermatol. 2016;152:992-1000.

2. Sławińska M, Sobjanek M, Olszewska B, Nowicki R,
Sokołowska-Wojdyło M. Trichoscopic spectrum of folliculotropic mycosis fungoides. J Eur Acad Dermatol Venereol. 2018;32:e107-8.

3. Geller S, Rishpon A, Myskowski PL. Dermoscopy in folliculotropic mycosis fungoides - A possible mimicker of follicle-based inflammatory and infectious disorders. J Am Acad Dermatol. 2019;81:e75-6.

4. Caccavale S, Vitiello P, Franco R, Panarese I, Ronchi A, Sica A, et al. Dermoscopic characterization of folliculotropic mycosis fungoides selectively localized on trunk and limbs. Int J Dermatol. 2019;58:e187-9.

5. Ghahramani GK, Goetz KE, Liu V. Dermoscopic characterization of cutaneous lymphomas: A pilot survey. Int J Dermatol. 2018;57:339-43.

6. Jurakic Toncic R, Ledic Drvar D, Bradamante M, Rados J, Jerkovic-Gulin S, Caccavale S, et al. Early dermoscopic sign of folliculotropism in patients with mycosis fungoides. Dermatol Pract Concept. 2018;8:328-9.

7. Jurakić Tončić R, Radoš J, Ćurković D, Ilić I, Caccavale S, Bradamante M. Dermoscopy of syringotropic and folliculotropic mycosis fungoides. Dermatol Pract Concept. 2020;10:e2020069.

Copyright by Linda Manaa, et al. This is an open access article distributed under the terms of the Creative Commons Attribution License, which permits unrestricted use, distribution, and reproduction in any medium, provided the original author and source are credited.

Source of Support: Nil, Conflict of Interest: None declared. 